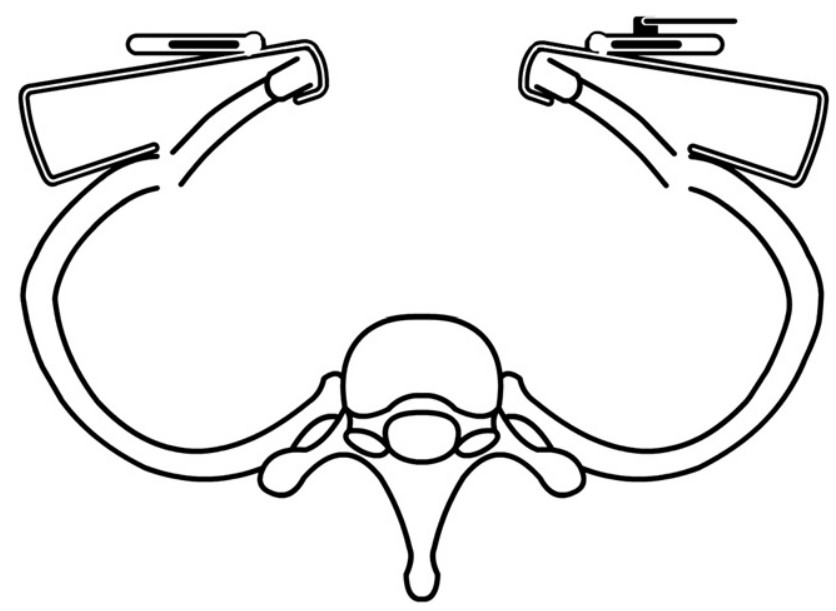

FIGURE 2. Cross-sectional view of the thorax with introduced sternal retractor and bilateral elevating plates.

A period of thorough bleeding control was necessary. The sternum was closed by cerclage with 8 wires, and the pectoral muscles were attached to the sternal bone with wound drainages placed underneath, followed by standard wound closure in layers.

The patient's postoperative course was uneventful. The patient remained in a hemodynamically and respiratory stable condition. After loading with phenprocoumon, the patient could be discharged.

The postoperative routine examination after 3 months showed an excellent result (Figure 1, B). The patient expressed satisfaction but did report feeling a slight restriction when bending forward, although he already had noticed an improvement. We anticipate that this dysesthesia will continue to dissipate over time.

\section{DISCUSSION}

Concomitant repair of pectus excavatum and cardiac defects is controversial. Leaving the deformity untreated may lead to problematic exposure of the heart or even cardiac impairment. ${ }^{1}$ Many authors consider midsternotomy inappropriate for concomitant repair. ${ }^{2-5}$ Although opinions diverge, it seems obvious that the worse the chest wall deformity, the more it will affect heart function and regeneration after staged repair. In very severe cases such as this one, it is morphologically impossible to correct the heart without correcting the chest wall.

We have demonstrated an approach by midsternotomy. Especially in patients with mitral valve deficiency, many of alternatively described approaches seem inadequate. Owing to the extensive wound area, particular care must be taken to control bleeding.

Our patient's smooth recuperation proves that a concomitant repair using midsternotomy can be the treatment of choice in severe cases of pectus excavatum.

\section{References}

1. Okay T, Ketenci B, Imamoglu OU, Aydemir B, Tuygun AK, Ozay B, Yapici F, Coruh TK, Demirtas MM. Simultaneous open-heart surgery and pectus deformity correction. Surg Today. 2008;38:592-6.

2. Doty DB, Hawkins JA. A turnover operation for pectus excavatum at the time of correction of intracardiac defects. J Thorac Cardiovasc Surg. 1983;86: 787-90.

3. Jones WG, Hoffman L, Devereux RB, Isom OW, Gold JP. Staged approach to combined repair of pectus excavatum and lesions of the heart. Ann Thorac Surg. 1994; 57:212-4.

4. Karl TR. A technique for concurrent repair of pectus excavatum and intracardiac defects. J Card Surg. 1988;3:487-9.

5. Miller DR, Pugh DM. Repair of ascending aortic aneurysm and aortic regurgitation complicated by acute cardiac compression by pectus excavatum in Marfan's syndrome. J Thorac Cardiovasc Surg. 1970;59:673-84.

\title{
A rare case of vascular ring: Retroesophageal artery between the right brachiocephalic artery and the left descending aorta
}

\author{
Yoshio Ootaki, MD, PhD, ${ }^{\mathrm{a}}$ Mohamed Sulaiman, $\mathrm{MD},{ }^{\mathrm{b}}$ and Ross $\mathrm{M}$. Ungerleider, $\mathrm{MD},{ }^{\mathrm{a}}$ Cleveland, Ohio
}

From the Divisions of Pediatric Cardiothoracic Surgery ${ }^{\mathrm{a}}$ and Pediatric Cardiology, ${ }^{\mathrm{b}}$ Rainbow Babies and Children's Hospital, University Hospitals Case Medical Center, Cleveland, Ohio.

Disclosures: None.

Received for publication June 7, 2010; accepted for publication June 14, 2010; available ahead of print July 20, 2010.

Address for reprints: Yoshio Ootaki, MD, PhD, Pediatric Cardiothoracic Surgery,

Rainbow Babies and Children's Hospital, 11100 Euclid Ave, Cleveland, OH 44106 (E-mail: y.ootaki@nifty.com).

J Thorac Cardiovasc Surg 2010;140:e76-7

$0022-5223 / \$ 36.00$

Copyright (c) 2010 by The American Association for Thoracic Surgery

doi:10.1016/j.jtcvs.2010.06.019
A vascular ring is a congenital aortic arch anomaly that presents with tracheal and esophageal compression by vascular structures. Vascular rings have been classified according to embryologic, pathologic, and radiographic criteria. We describe a very rare vascular ring due to an abnormal retroesophageal artery in an infant.

\section{CLINICAL SUMMARY}

A 5-month-old baby was referred to our hospital because of long-standing wheezing and difficulty feeding. Gastroesophagographic analysis revealed compression of the esophagus, 


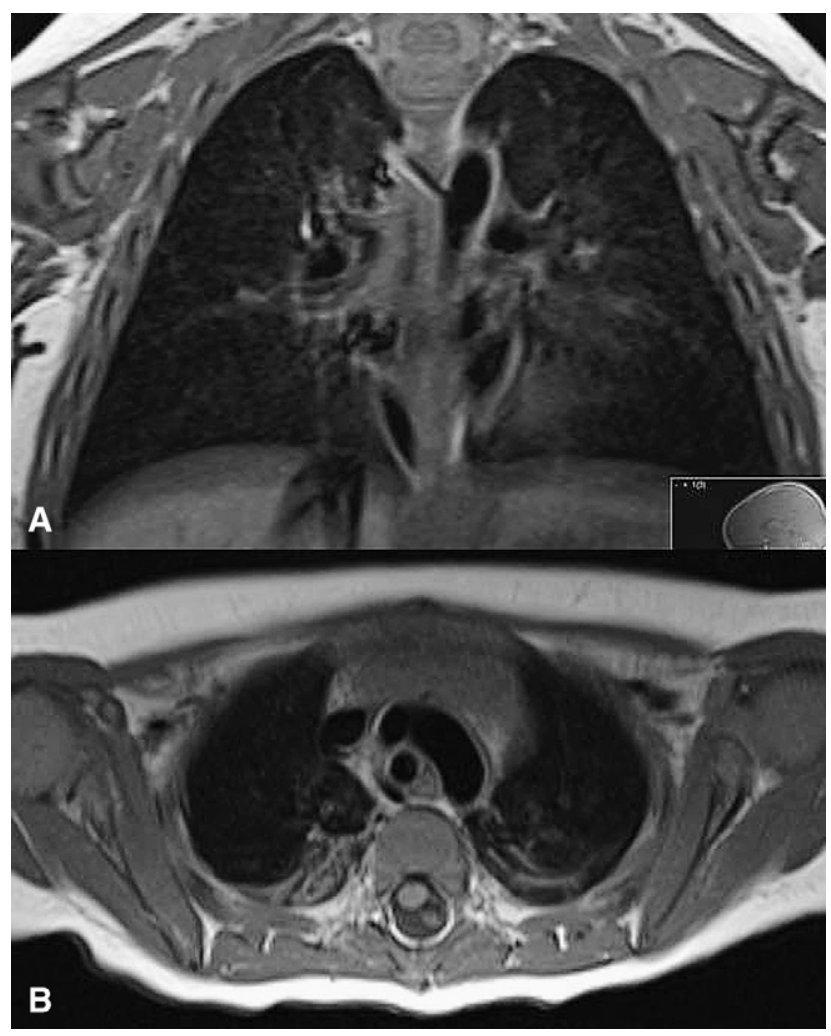

FIGURE 1. Magnetic resonance imaging of the coronal view (A) and transverse view (B) revealed that there was an abnormal retroesophageal artery between the right brachiocephalic artery and the left descending aorta.

which suggested the existence of an aberrant right subclavian artery with normal left aortic arch. Magnetic resonance imaging revealed a normal left aortic arch with a right brachiocephalic artery, left common carotid artery, and left subclavian artery. There was a fourth vessel arising from the medial arch just beyond the left subclavian origin (Figure 1, A). This vessel measured approximately $2 \mathrm{~mm}$ in diameter and passed posterior to the trachea and esophagus, taking a course similar to that of a classic aberrant right subclavian artery. This aberrant vessel appeared to converge with the right brachiocephalic bifurcation (Figure 1, $B$ ). This artery created a complete vascular ring (Figure 2). Magnetic resonance imaging also revealed significant narrowing of the distal trachea. Surgical intervention was performed through a left thoracotomy. The left ductal ligament and abnormal artery were divided in the same manner as division of a classic aberrant right subclavian artery. Although the patient had chylothorax, after conservative therapy, he was discharged from the hospital. His respiratory symptoms were improved after the operation.

\section{DISCUSSION}

According to the vascular structure of the vascular ring, these anomalies have been well analyzed and classified in

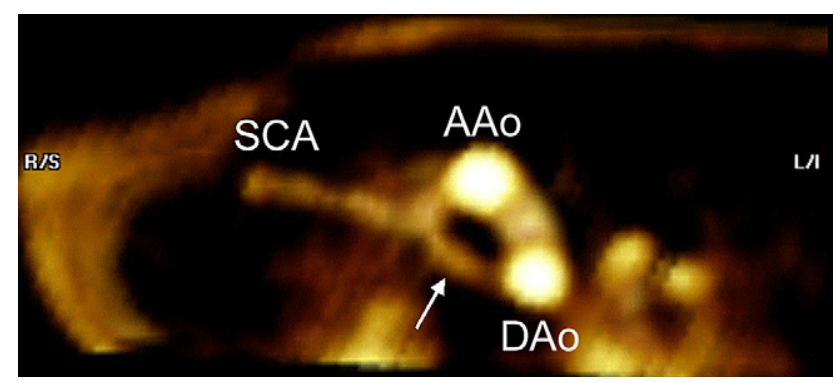

FIGURE 2. Three-dimensional reconstruction image of the thoracic aorta. Complete vascular ring consisted of the normal left aortic arch, brachiocephalic artery, and abnormal retroesophageal artery (arrow). Both the trachea and esophagus went through the vascular ring. AAo, Ascending aorta; $D A o$, descending aorta; $S C A$, right subclavian artery.

the literature as 5 distinct types, including (1) double aortic arch, (2) right aortic arch with left ligamentum, (3) left aortic arch with aberrant (retroesophageal) right subclavian artery, (4) pulmonary artery sling, and (5) innominate artery compression. ${ }^{1-3}$ A left aortic arch with aberrant right subclavian artery is not typically a complete vascular ring, although this anatomy can create symptoms caused by compression of the esophagus and trachea. In this case, however, the aberrant subclavian artery joined the brachiocephalic artery at the takeoff of the normal right subclavian artery, thus creating a complete ring. This vascular ring case report does not fit any previous reported classification. Holmberg and Presnell ${ }^{4}$ reported a vascular ring caused by a similar aberrant vessel in a dog. This case is a very rare anomaly, and this is the first human clinical report in the literature to our knowledge.

A left aortic arch associated with an aberrant right subclavian artery is the most common aortic arch anomaly, with an incidence of $1 \%$ to $2 \% .{ }^{5}$ However, it rarely causes clinical symptoms. If there is a compression symptom of the trachea and esophagus in a patient with a normal left aortic arch, existence of an aberrant right subclavian artery, as well as the above anatomy, should be suspected.

\section{References}

1. Backer CL, Mavroudis C. Congenital Heart Surgery Nomenclature and Database Project: vascular rings, tracheal stenosis, pectus excavatum. Ann Thorac Surg. 2000;69:S308-18

2. Ruzmetov M, Vijay P, Rodefeld MD, Turrentine MW, Brown JW. Follow-up of surgical correction of aortic arch anomalies causing tracheoesophageal compression: a 38-year single institution experience. J Pediatr Surg. 2009;44: 1328-32.

3. Humphrey C, Duncan K, Fletcher S. Pediatrics. Decade of experience with vascular rings at a single institution. Pediatrics. 2006;117:e903-8.

4. Holmberg DL, Presnell KR. Vascular ring anomalies: case report and brief review. Can Vet J. 1979;20:78-81.

5. Karcaaltincaba M, Haliloglu M, Ozkan E, Kocak M, Akinci D, Ariyurek M. Noninvasive imaging of aberrant right subclavian artery pathologies and aberrant right vertebral artery. Br J Radiol. 2009;82:73-8. 